\title{
Torsional strength evaluation of reinforced SCC box beams strengthened internally by opened and closed transverse concrete diaphragms
}

\author{
Ali Aziz ${ }^{1, *}$, and Oday Hashim ${ }^{1}$ \\ ${ }^{1}$ Faculty of Engineering, Al-Mustansiriayah University, Baghdad, Iraq.
}

\begin{abstract}
There are a few researches about box (hollow core) RC beams under the effect of torque moment; therefore, a torsional failure mechanism is not understood well. In the present paper, the concept (technique) of adding internal concrete diaphragms, in transverse direction, is adopted. Six self-compacting concrete beam specimens having a dimension of $(2200 \times 220 \times 350 \mathrm{~mm})$ for length, width and height, respectively were poured and tested. Three variables are adopted in the present study, section type, number and type of the internal diaphragms. Experimental results show that the ultimate torque moment increases about (43\%-61\%) and (89\%-94\%) for beam specimens strengthened internally by two and four diaphragms respectively. Also, increasing internal diaphragms from two to four, led to increase the ultimate torque moment about (33\%-46\%). Furthermore, the change of section from box section with four internal diaphragms to solid section, led to increase in ultimate torque moment about (28\%-33\%). The paper concludes that the increase in torsional capacity is attainable for box (hollow core) beams by using the technique of strengthening by internal diaphragms; Also, the box sections can be made with internal opened diaphragms and possess same capacity or contribution of the closed ones.
\end{abstract}

\section{Introduction}

A box concrete section (or hollow core beam or box beam or hollow beam) is often used for beam design, particularly for long spans bridges for reducing dead load and saving cost construction. Many structural members such as building and bridge elements are subjected to equilibrium torsional moments. In order to avert failure of these elements at torsional load, adequate reinforcement (longitudinal and transverse), repairing and strengthening are required. Strengthening of concrete members to resist torsional stresses may be achievable by one of the following techniques: (i) increasing the member cross-sectional area, (ii) adding transverse reinforcement, (iii) using externally bonded steel plates, (iv) applying an axial load to the member by external prestressing $[1,2]$.

Reinforced concrete sections under torsional stresses and externally strengthened by CFRP are interested in several research $[3,4]$. Beams reinforced internally with GFRP reinforcements under pure torsion are also interested [5].

Due to rapid development in concrete technology and construction techniques, new concrete types such as SCC has emerged. Many researches showed that SCC is commonly used within precast and cast-in-place construction. Furthermore, it is also used in the thin concrete members and where the steel reinforcement tightness is required. However, other implementations of
SCC include caissons, drilled piers, walls and bridge abutments [6].

There are few researches about box reinforced concrete beams under the effect of torque moment; therefore, a torsional failure mechanism is not understood well. The concept of adding internal concrete diaphragms (opened or closed), in transverse direction is a new technique for strengthening reinforced concrete box (hollow core) sections under the effects of torsional stresses and will be adopted in the present study. It may be noted that, additional variables can be added later to the present study as a suggestions for future researches.

\section{Research Significance}

Despite the many investigations on the torsional behavior of reinforced concrete beams with solid or hollow cross section, little has been done on the applications of SCC with a complete absent for strengthening internally by any techniques. So the need to study the torsional behavior of such sections with strengthening by special technique gives more attention. The main objectives of the current study is to investigate, experimentally, torsional behavior of reinforced SCC rectangular box (hollow core) beams strengthening transversely by internal diaphragms with different variables, including, type of section (solid or box), number and type of the internal diaphragms (closed or opened).

*Corresponding author: alihaziz@uomustansiriyah.edu.iq 


\section{Experimental program}

The experimental program consists of cast and test of six reinforced SCC beam specimens. One specimen was control beam; four beams were strengthened using internal diaphragms while the last beam was a solid. Three variables were adopted in the present study, section type (solid or box), number and type of the internal diaphragms (closed or opened). The specimen's dimensions, clear span, concrete grade, load location and reinforcement (longitudinal and transverse) were kept constant thought out this study. The experimental work includes, also, a series of tests carried out on control specimens (cubes and cylinders). Cracking load, ultimate load, mode of failure, torque-angle of twist behavior and torque-strain curve are recorded, discussed and presented in this study.

\subsection{Beam specimens description}

The specimens have a dimension of $(2200 \times 220 \times 350 \mathrm{~mm})$ for length, width and height respectively. Since, the hollow and solid reinforced concrete beams can be designed directly according to ACI-318 code ${ }^{[7]}$, the longitudinal and transverse reinforcement were calculated based on code requirement for torsion. Each beam was reinforced by $(2 \phi 12 \mathrm{~mm})$ bars at the top and bottom, while, the transverse reinforcement consists of ( $\phi 10 @ 60 \mathrm{~mm})$ stirrups at edges and ( $\phi 10 @ 120 \mathrm{~mm})$ stirrups at the mid, see Figure (1). As mentioned before, the concept of strengthening of hollow sections by transverse internal diaphragms (to resist torsional stresses) are adopted in the present paper. Therefore, lateral (transverse) closed or opened diaphragms with thickness of $(50 \mathrm{~mm})$ were created (during concrete poured) inside the hollow beam specimens. It may be noted that, all diaphragms were reinforced longitudinally (vertically) and transversely by $(6 \phi 10 \mathrm{~mm})$ and $(4 \phi 10 \mathrm{~mm})$ bars respectively. Each beam specimen was designated in a way to refer to section type $(\mathrm{HB}=$ Hollow Beam or $\mathrm{SB}=$ Solid Beam), number of internal diaphragms (0,2 and 4) and type of diaphragm ( $\mathrm{CD}=$ Closed Diaphragm, $\mathrm{OD}=$ Opened Diaphragm). Therefore, for example, the beam specimen (HB-4CD) is a hollow beam made with four transverse closed diaphragms. Description and details of tested beam specimens are shown in Table (1) and Figures (2) to (8).

Table 1. Beam Specimens Description

\begin{tabular}{|c|c|c|c|c|}
\hline \multirow{2}{*}{ Beam } & \multicolumn{3}{|c|}{ Dimensions (mm) } & \multirow{2}{*}{ Description } \\
\hline & $\mathbf{L}$ & W & D & \\
\hline HB-0D* & \multirow{6}{*}{2200} & \multirow{6}{*}{220} & \multirow{6}{*}{350} & Hollow \\
\hline HB-2CD & & & & $\begin{array}{l}\text { Hollow With Two } \\
\text { Closed Diaphragms }\end{array}$ \\
\hline HB-2OD & & & & $\begin{array}{c}\text { Hollow With Two } \\
\text { Opened } \\
\text { Diaphragms }\end{array}$ \\
\hline $\mathrm{HB}-4 \mathrm{CD}$ & & & & $\begin{array}{l}\text { Hollow With Four } \\
\text { Closed Diaphragms }\end{array}$ \\
\hline HB-4OD & & & & $\begin{array}{c}\text { Hollow With Four } \\
\text { Opened } \\
\text { Diaphragms }\end{array}$ \\
\hline SB & & & & Solid \\
\hline
\end{tabular}

Reference Beam

Note: $\mathrm{HB}=$ Hollow Beam, $\mathrm{CD}=$ Closed Diaphragm, $\mathrm{OD}=$ Opened Diaphragm, $\mathrm{SB}=$ Solid Beam

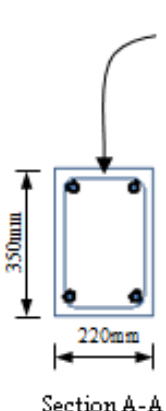

\$10@60/120mm Stirrups

Section A-A

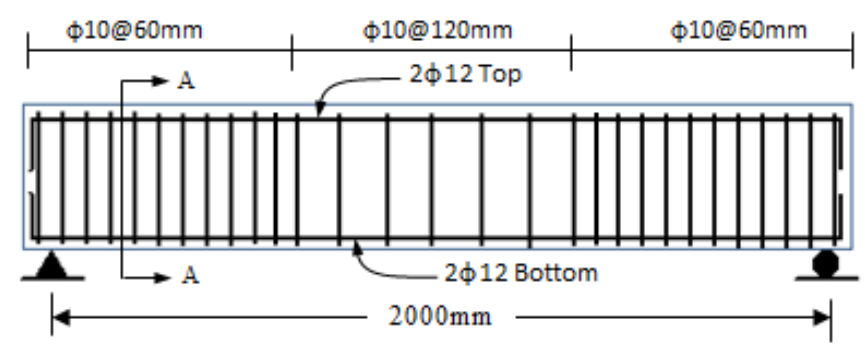

Fig.1. Reinforcement Details and Dimensions of the Tested Beams

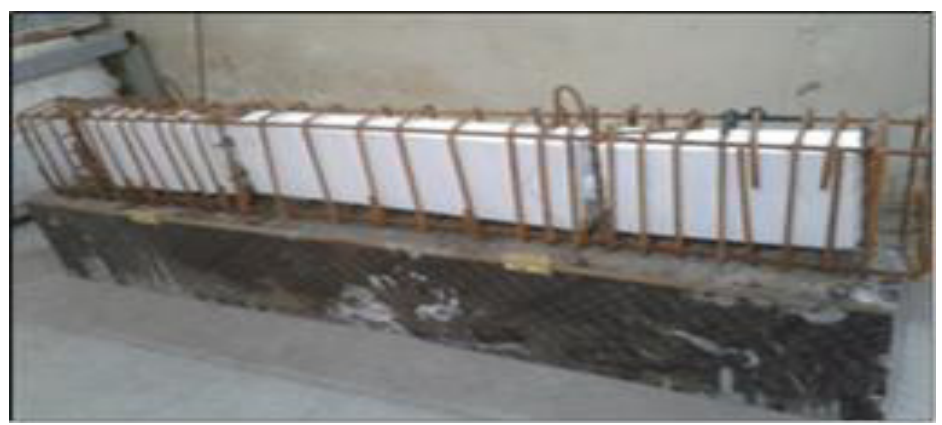


Fig. 2. Reinforcement Details and Diaphragms Location

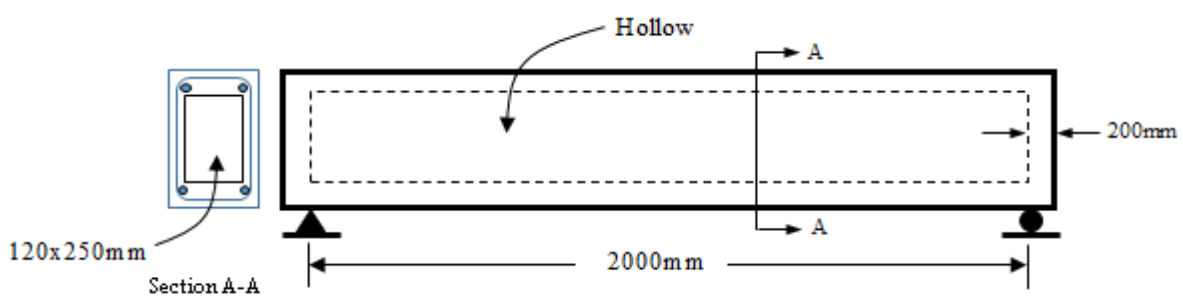

Fig. 3. Description of Beam Specimen (HB-0D)

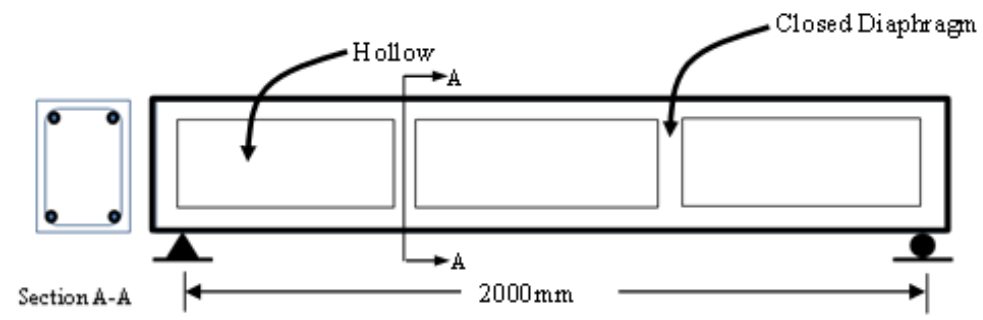

Fig. 4. Description of Beam Specimen (HB-2CD)

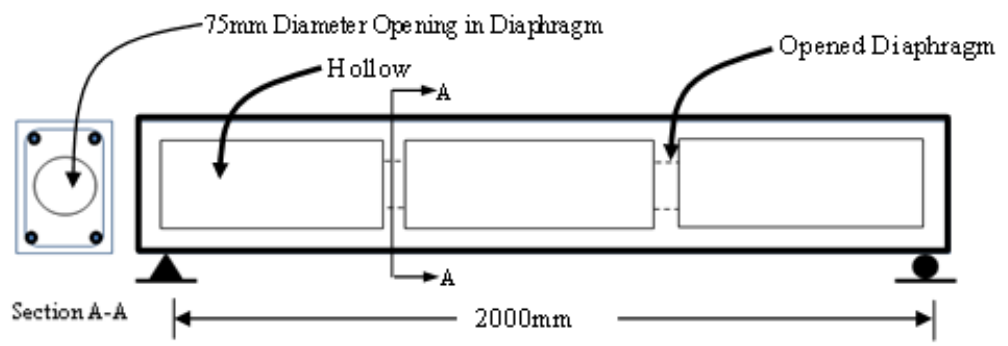

Fig. 5. Description of Beam Specimen (HB-2OD)

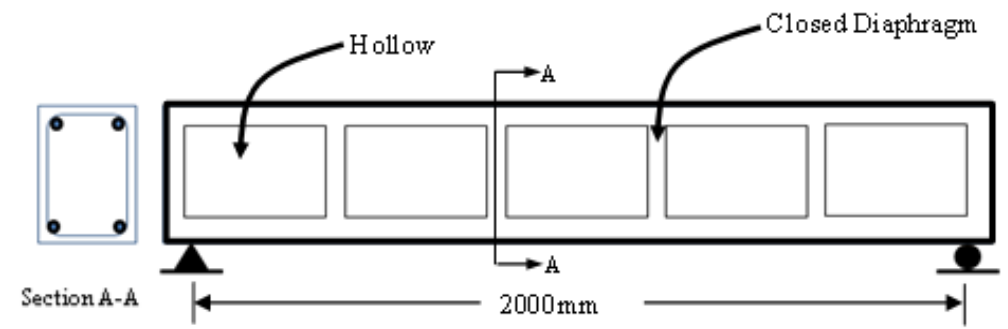

Fig. 6. Description of Beam Specimen (HB-4CD)

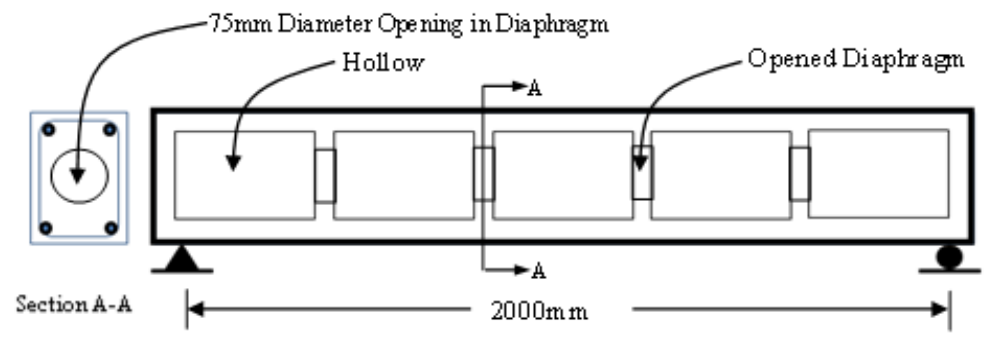

Fig. 7. Description of Beam Specimen (HB-4OD) 


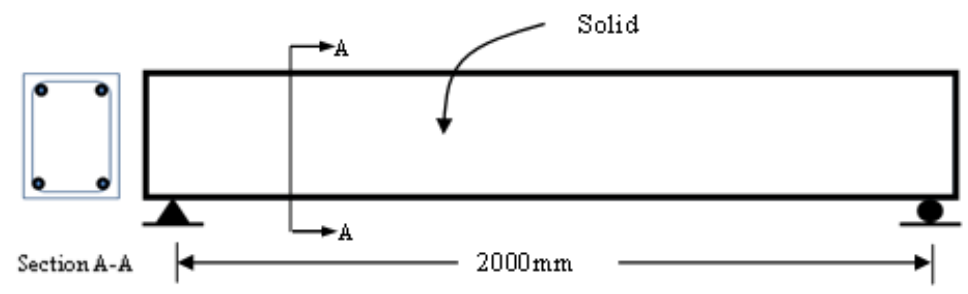

Fig. 8. Description of Beam Specimen (SB)

\subsection{Molds}

One wooden mold with $(18 \mathrm{~mm})$ thickness has been used for casting the beam specimens. The mold consists of a bed and four movable sides, these sides have been fixed to the bed by screws. The clear dimensions of the mold were $(2200 \times 220 \times 350 \mathrm{~mm})$ for length, width and height respectively. For casting the mold was oiled and the required reinforcement cage was placed inside the mold before casting the concrete batch.

To form the box beam, the cross section contains a polystyrene void that blocks out the center of the beam over specified lengths. The void is included to block out concrete where it does not add much resistance to the section and reduce the self-weight of the beam. For practical reasons, the void (box) in the beam crosssection is obtained by a stay-in-place polystyrene blocks. It may be noted that, the closed diaphragms are created directly when the spacing between Polystyrene blocks are filled by SCC during the pouring process. While, to create opened diaphragms, UPVC pipe of diameter of $(75 \mathrm{~mm})$ is restricted between polystyrene pieces. For all tested beams, beyond the cells (at the ends), whole beam section $(220 \times 350 \mathrm{~mm})$ was solid concrete.

\subsection{Materials}

To manufacture the test beams, properties and description of the used materials are reported and presented in Table (2); and mix proportions of concrete (by weight) are reported and presented in Table (3).

\section{Measurements and Instrumentation}

All beams as well as control specimens were tested by using Hydraulic Testing Machine (MFL type) with a maximum range capacity of $(3000 \mathrm{kN})$, Figure (9). To ensure free rotation at supports, spherical bearing seats are used as shown in Figure (10). To determine the angle of twist, simple method was used by fixing a dial gauge to the beam ends (at the bottom at a point $45 \mathrm{~mm}$ from longitudinal axis of the beam) as shown in Figure (11). The gauge $(0.01 \mathrm{~mm} /$ div. accuracy) recorded the vertical displacement to estimate the angle of twist (in radians) at every load stage.

Table 2. Properties of Construction Materials

\begin{tabular}{|l|l|}
\hline \multicolumn{1}{|c|}{ Material } & \multicolumn{1}{|c|}{ Descriptions } \\
\hline Cement & Ordinary Portland Cement (Type I) \\
\hline Sand & $\begin{array}{l}\text { Natural sand with maximum size of } \\
(4.75 \mathrm{~mm})\end{array}$ \\
\hline Gravel & Crushed gravel of maximum size (14 mm) \\
\hline Limestone powder & Fine limestone powder of Jordanian origin \\
\hline Superplasticizer & $\begin{array}{l}\text { Sika viscocrete-5930 manufactured by } \\
\text { BASF Construction Chemicals }\end{array}$ \\
\hline & $\begin{array}{l}(\phi 12 \mathrm{~mm}) \text { deformed steel bar, having (495 } \\
\text { MPa yield strength }\left(f_{y}\right) \\
(\phi 10 \mathrm{~mm}) \text { deformed steel bar, having (510 } \\
\text { MPa) yield strength }\left(f_{v}\right)\end{array}$ \\
\hline Weinforcing Bars & Clean tap water \\
\hline
\end{tabular}


Table 3. Concrete Mix Proportions

\begin{tabular}{|l|c|c|c|}
\hline \multicolumn{1}{|c|}{ Material } & Quantity & Ratio & Limits \\
\hline Cement $\left(\mathrm{Kg} / \mathrm{m}^{3}\right)$ & 450 & & $350-600$ \\
\hline Sand $\left(\mathrm{Kg} / \mathrm{m}^{3}\right)$ & 750 & $33 \%^{\mathrm{a}}$ & $<40 \%$ \\
\hline Gravel $\left(\mathrm{Kg} / \mathrm{m}^{3}\right)$ & 900 & $40 \%^{\mathrm{b}}$ & $<50 \%$ \\
\hline Silica fume $\left(\mathrm{Kg} / \mathrm{m}^{3}\right)$ & 30 & & \\
\hline Limestone $\left(\mathrm{Kg} / \mathrm{m}^{3}\right)$ & 130 & & \\
\hline Super plasticizer $\left(\mathrm{L} / \mathrm{m}^{3}\right)$ & 10 & $1.64 \%^{\mathrm{c}}$ & $<2 \%$ \\
\hline Water $\left(\mathrm{L} / \mathrm{m}^{3}\right)$ & 190 & & \\
\hline W/P $(\%)$ & & $31.1^{\mathrm{d}}$ & $28 \%-38 \%$ \\
\hline
\end{tabular}

a-Sand ratio $=$ Sand $/($ cement + sand + gravel + silica fume + limestone $)$

b-Gravel ratio $=$ Gravel/(cement + sand + gravel + silica fume + limestone $)$

c-Super plasticizer ratio $=$ Super plasticizer/(cement content + silica fume + limestone $)$ $\mathrm{d}-\mathrm{W} / \mathrm{P}=\mathrm{Water} /($ cement content + silica fume + limestone $)$

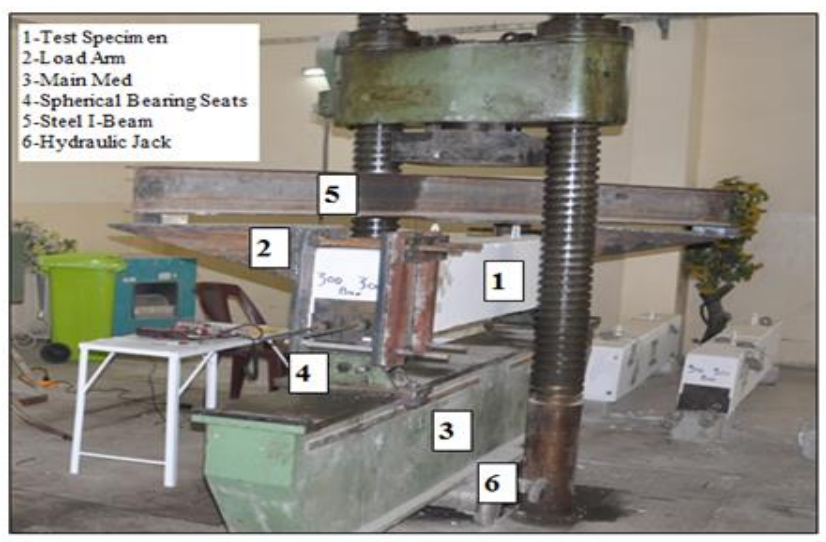

Fig. 9. Test Machine and Beam Setup

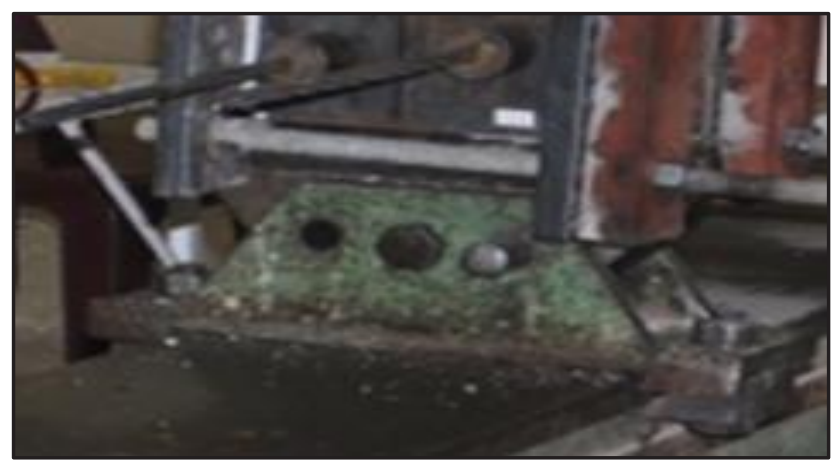

Fig. 10. Spherical Bearing Seats at Supports

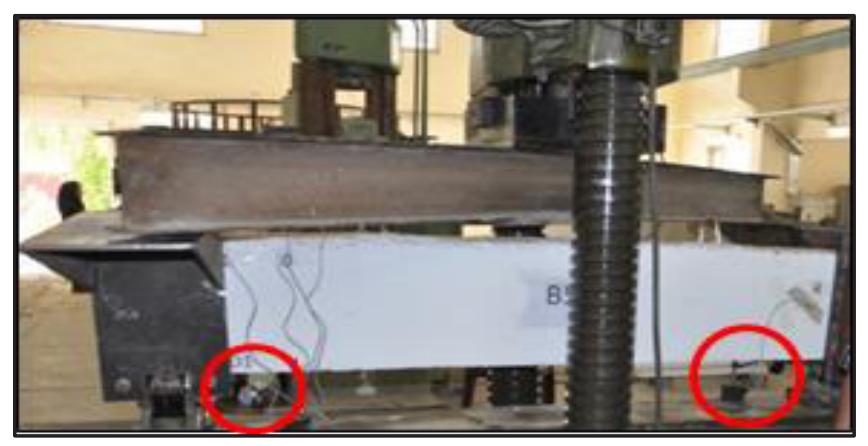

Fig. 11. Locations of Dial Gages 


\section{Testing procedure}

The testing machine, shown in Figures (9) and (11), was used to test all beam specimens as well as control samples. The vertical load can be applied directly on the beam specimens at any point and the bearings should remain fixed without any rotation around the beam's longitudinal axis. In the present study, the applied loads outside the bed of the test machine were needed in order to get the torsional movement. The test requirements need to:-

a- Create ball bearing (move the supports in a circular manner).

b- Transmitting the load from the center of the test machine to the two external points (moment arm). In this paper, the used clamping frame (loading frame) is shown in Figures (9) and (11). The steel frame consist of two clamps work as an arms for applied torque moment with separated faces to connect them over the beam by means of bolts (for each arm, four bolts were used). The frame is made with two steel shafts of thick steel plate of $(20$ $\mathrm{mm}$ ) attached by welding. The final shape of the steel frame is look like to a bracket. The steel arms are capable to provide eccentricity of a maximum of $(600$ $\mathrm{mm}$ ) with respect to the beam longitudinal axis. To transmit the applied loads from the center of the test machine to the arms, steel girder of $(2 \mathrm{~m})$ length and $(250 \mathrm{~mm})$ depth was used. The steel girder was fixed to the machine of test, as shown in Figures (9) and (11).

\section{Characteristics of SCC}

\subsection{Characteristics of fresh SCC}

Four tests to evaluate three characteristics (filling ability, segregation resistance and passing ability) are made to check self-compacting concrete. Table (4) shows the test methods, test results and SCC requirements according to EFNARC [8]. Tests results show that the used SCC confirmed to standard requirements.

\subsection{Characteristics of hardened SCC}

All control specimens (cylinders and cubes) were removed from curing at the age of (28 days). Compressive strength of SCC for cylinders and cubes are measured based on ASTM C39-96 ${ }^{[9]}$ and BS1881-116 ${ }^{[10]}$ respectively. Tests results are reported and presented in Table (5).

Table 4. Test Results of Fresh SCC

\begin{tabular}{|c|c|c|c|}
\hline Test & Property & $\begin{array}{c}\text { Test } \\
\text { Result }\end{array}$ & EFNARC \\
\cline { 1 - 1 } Slump $(\mathrm{mm})$ & Filling & 800 & $650-800$ \\
\cline { 1 - 1 } \cline { 3 - 4 } $\mathrm{T}_{50}(\mathrm{sec})$ & ability & 2.81 & $2.0-5.0$ \\
\hline $\begin{array}{c}\text { V-funnel } \\
(\mathrm{sec})\end{array}$ & $\begin{array}{c}\text { Segregation } \\
\text { Resistance }\end{array}$ & 8.28 & $6.0-12$ \\
\hline L-Box & $\begin{array}{c}\text { Passing } \\
\text { ability }\end{array}$ & 1.0 & $0.8-1.0$ \\
\hline
\end{tabular}

Table 5. Test Results of Hardened SCC

\begin{tabular}{|l|c|}
\hline \multicolumn{1}{|c|}{ Property } & $\begin{array}{c}\text { Test } \\
\text { Result }\end{array}$ \\
\hline Cube Compressive Strength $\left(f_{\mathrm{cu}}\right), \mathrm{MPa}$ & 41 \\
\hline Cylinder Compressive Strength $\left(f_{c}^{\prime}\right), \mathrm{MPa}$ & 38 \\
\hline
\end{tabular}

\section{Test results}

\subsection{Cracking and ultimate load}

The results of cracking torque (Tc) and ultimate torque (Tu) are shown in Table (6) for all tested beam specimens. The ultimate torque increases about (61\%) and (94\%) for beam specimens (HB-2CD and HB-4CD) which strengthened internally by two and four closed diaphragms respectively. While, for beam specimens (HB-2OD and HB-4OD) who strengthened internally by two and four opened diaphragms, the ultimate torque increases about $(43 \%)$ and $(89 \%)$ respectively. In comparison with the reference beam, (HB-0D), the cracking torque increases about $(57 \%)$ and $(100 \%)$ for beam specimens (HB-2CD and HB-4CD) which are strengthened internally by two and four closed diaphragms, respectively. While, for beam specimens (HB-2OD and HB-4OD) who strengthened internally by two and four opened diaphragms, the cracking torque increases about (29\%) and (86\%), respectively. This means the presences of internal diaphragms improves the torsional resistance and allow higher forces to be carried through internal diaphragms. When the beam section changes from box section (HB-0D) (without internal diaphragms) to solid section (SB), the cracking torque and ultimate torque increase by $(43 \%)$ and $(122 \%)$, respectively. For box beam specimen, only the thinned wall (ribs) is contributed to resist both, cracking and ultimate loads. From the other hand, full section of solid beam (SB) is contributed to resist both, cracking and ultimate loads. The results indicated that the increase in torsional capacity is attainable for box (hollow core beams) by using the concept of strengthening by internal opened or closed diaphragms.

Table 6. Test Results of Beam Specimens

\begin{tabular}{|c|c|c|c|c|}
\hline Beam & $\begin{array}{c}\text { Tc } \\
\text { (kN.m) }\end{array}$ & $\begin{array}{c}\text { Increase } \\
\text { in Tc* }\end{array}$ & $\begin{array}{c}\text { Tu } \\
(\mathbf{k N . m})\end{array}$ & $\begin{array}{c}\text { Increase } \\
\text { in Tu* }\end{array}$ \\
\hline HB-0D & 5.25 & - & 17.25 & - \\
\hline HB-2CD & 8.25 & $57 \%$ & 27.75 & $61 \%$ \\
\hline HB-2OD & 6.75 & $29 \%$ & 24.75 & $43 \%$ \\
\hline HB-4CD & 10.5 & $100 \%$ & 33.45 & $94 \%$ \\
\hline HB-4OD & 9.75 & $86 \%$ & 32.55 & $89 \%$ \\
\hline SB & 7.5 & $43 \%$ & 38.25 & $122 \%$ \\
\hline
\end{tabular}

\subsection{Modes of failure}

The progress of cracks provided useful information regarding the failure mechanism of tested specimens. First crack of all specimens occurred at mid span and increased gradually. When the torque moment was increased, cracks appeared on each side and finally took 
the spiral shape. Figures (12) to (14) show the mode of were failed by torsional spiral cracks (diagonal concrete cracks). For box beams, the extensive concrete cracking is bounded between diaphragms which ultimately resulted in beam failure. failure of the tested specimens. The beam specimens

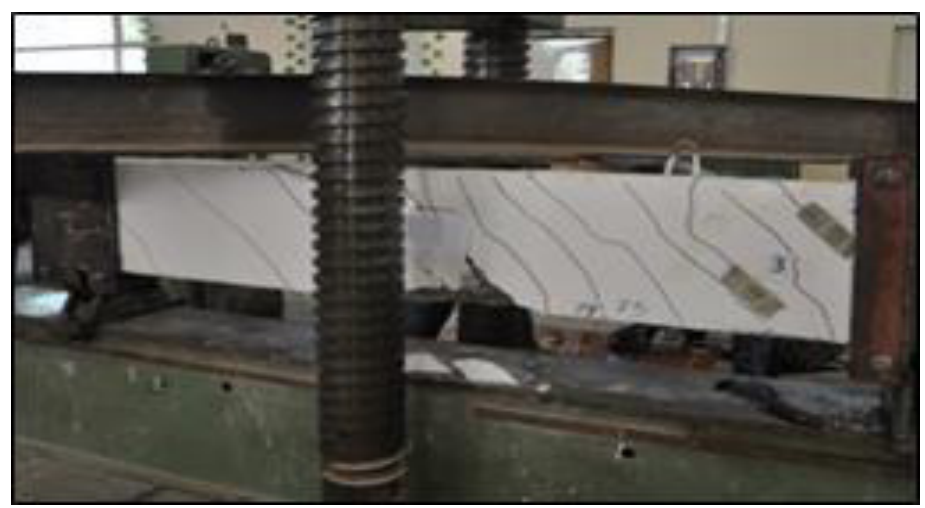

Fig. 12. Beam Specimens Failure Mode

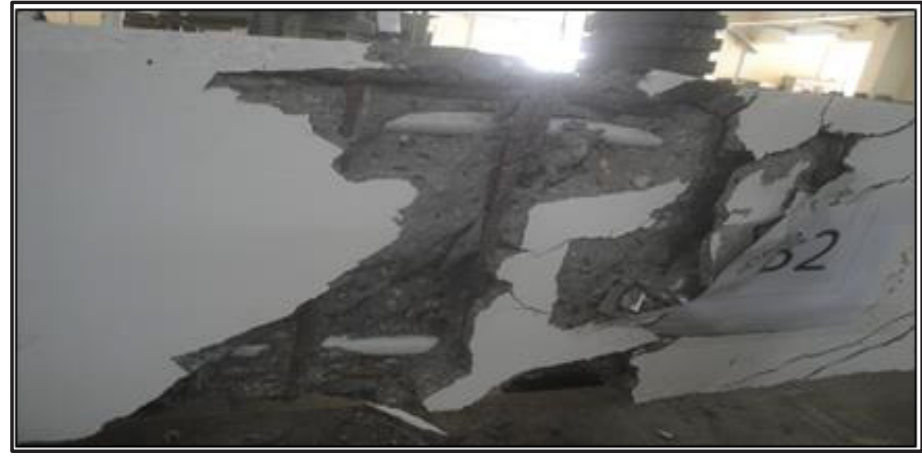

Fig. 13. Close-up Mode of Failure of Tested Beam

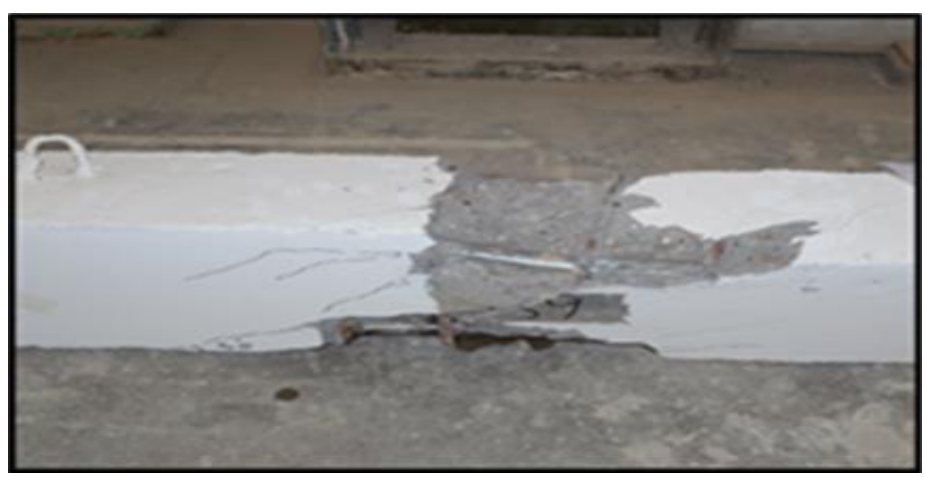

Fig. 14. Failure Mechanism of Tested Beam

\subsection{Effect of number of internal diaphragms}

As shown in Table (6), the ultimate torque increases about (43\%-61\%) for beam specimens (HB-2OD and HB-2CD) which are strengthened internally by two diaphragms. While, for beam specimens (HB-4OD and HB-4CD) which are strengthened internally by four diaphragms, the ultimate torque increases about $(89 \%$ $94 \%$ ). Also, increasing of internal diaphragms from two to four, led to increase the ultimate torque moment about
(33\%-46\%). From the other hand, the change of section from box section with four internal diaphragms to solid section, led to increase in ultimate torque moment by about $(28 \%-33 \%)$. This is due to increase in torsional stiffness due to presence of internal diaphragms or full solid section.

\subsection{Effect of type of internal diaphragms}


When the internal diaphragms changed from opened to closed type, the ultimate capacity increased about (3.6\%) and $(2.76 \%)$ for beam specimens containing two and four internal diaphragms respectively. Since the increase is marginal (can be negligible), it can be concluded that the box sections can be strengthened by internal opened diaphragms and possess same capacity or contribution of the closed ones.

\subsection{Effect of hollowness}

When the beam section changes from box section (HB0D) (without internal diaphragms) to solid section (SB), the cracking torque and ultimate torque increase by $(43 \%)$ and (122\%) respectively, see Table (6). For box beam specimen, only the thinned wall (ribs) is contributed to resist both, cracking and ultimate loads. From the other hand, full section of solid beam (SB) is contributed to resist both, cracking and ultimate loads.

\subsection{Torque-angle of twist behavior}

Figure (15) shows the relationship between torque and angle of twist (T- $\theta$ Diagram) for all beams. Ultimate angle of twist $(\theta)$ for all tested beam specimens are shown in Table (7). The strengthening using internal diaphragms can obviously change the deformation capacity of box beams. Test results indicated that the angle of twist was approximately constant at about $\left(15 \times 10^{-2}\right.$ radian $)$ until occurrence of the first crack then increased gradually until failure. Before the first crack, at the same level of torque, the angle of twist of strengthened beams was smaller than the angle of twist of control beams. Compared to the control beam (HB$0 \mathrm{D}$ ), the ultimate twist angle of beam specimens (HB-2CD), (HB-2-OD), (HB-4-CD) and (HB-4-OD) are increased by $(37 \%),(43 \%),(100 \%)$ and $(144 \%)$, respectively. This is may be due the transverse diaphragms that were placed inside the beam and that allowed to higher torque to be carried and as a result, the corresponding angle of twist was increased. Moreover for beam specimen (SB), the ultimate twist angle is increased slightly, about $(10 \%)$, as the test results indicated. This may be due to high rigidity of this beam (entire beam section will resist torsional stresses and as a result, the corresponding angle of twist decreased). For the control beam (HB-0D), the presence of hollow seems to be more effective in decreasing the crack torque and torsional capacity because the hollow decreased the section rigidity (the weakness extend throughout an entire the whole beam), as a result, the corresponding ultimate twist angle is decreased.

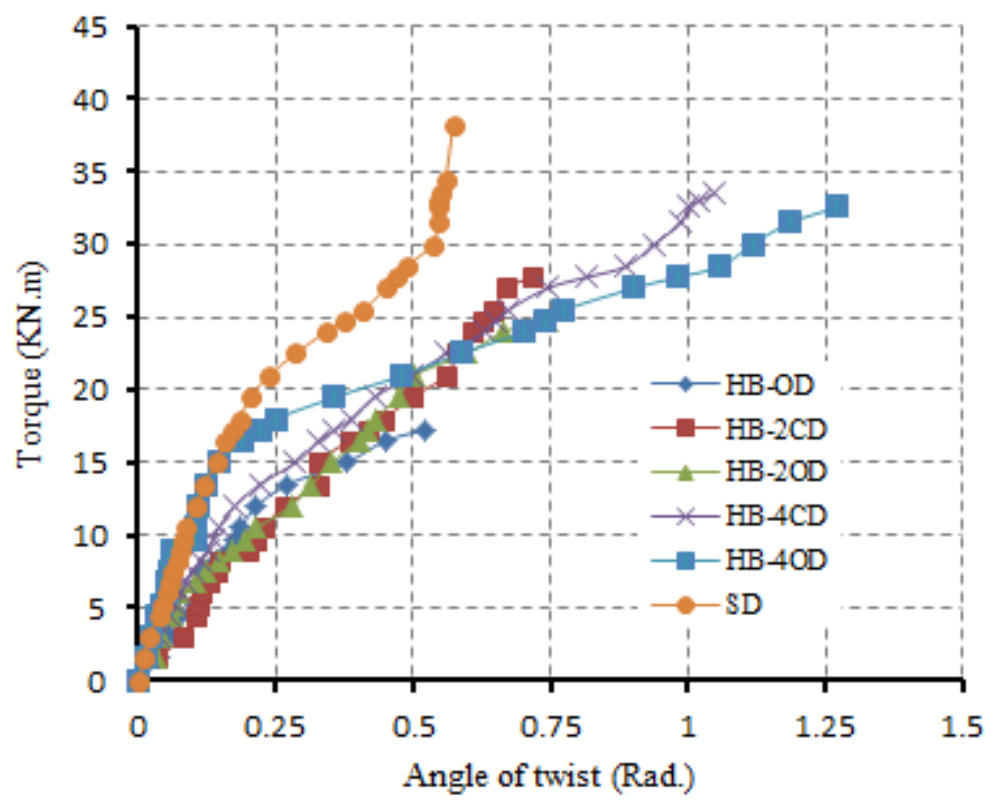

Fig 15. Torque-Angle of Twist Behavior

\subsection{Ductility}

The toughness may be considered as a ductility indicator. The toughness was measured as the area under the torque-angle of twist curve for each beam specimen using Microsoft Excel. In Table (7), it is noticed that toughness of the strengthened beam specimens (HB-2$\mathrm{CD})$, (HB-2-OD), (HB-4-CD) and (HB-4OD) is higher than reference beam (HB-0D). This might be because the strengthening by using internal transverse diaphragms led to increase both, torque and rotational (twisting) capacity and as a result, the toughness of these beams increased. Clearly in Table (7), when the number of internal diaphragms increased from two to four diaphragms, the corresponding toughness increased too. The unstrengthened reference beam (HB-OD) did not provide any restraint against rotation, and recodes lowest toughness. While, the solid beam (SB) provides high 
restraint against rotation (angle of twist) because entire section resists the torsional stresses and as a result, less angle of twist was recorded, even though the beam torsional capacity is high.

Table 7. Toughness of Tested Beam Specimens

\begin{tabular}{|c|c|c|c|}
\hline Beam & $\begin{array}{c}\boldsymbol{\theta} \\
\text { (Rad.) }\end{array}$ & $\begin{array}{c}\boldsymbol{\theta i} / \mathbf{\theta r} \\
\mathbf{( \% )}\end{array}$ & $\begin{array}{c}\text { Toughness } \\
(\mathbf{k N . m . ~ r a d )} \\
\mathbf{x 1 0}^{-4}\end{array}$ \\
\hline HB-0D & 0.5214 & - & 391 \\
\hline HB-2-CD & 0.7162 & 137 & 537 \\
\hline HB-2-OD & 0.7448 & 143 & 559 \\
\hline HB-4-CD & 1.0455 & 200 & 784 \\
\hline HB-4-OD & 1.2718 & 244 & 838 \\
\hline SB & 0.5729 & 110 & 430 \\
\hline
\end{tabular}

\section{Conclusions}

Based on experimental results, the following conclusions can be drawn:-

1-The ultimate torque moment increases about (61\%) and $(94 \%)$ for beam specimens which are strengthened internally by two and four closed diaphragms respectively. While, for beam specimens which are strengthened internally by two and four opened diaphragms, the ultimate torque increases about (43\%) and $(89 \%)$, respectively.

2- The cracking torque moment increases about (57\%) and $(100 \%)$ for beam specimens which are strengthened internally by two and four closed diaphragms, respectively. While, for beam specimens that are strengthened internally by two and four opened diaphragms, the cracking torque increases about (29\%) and $(86 \%)$, respectively.

3- When the section changes from the box section, (without internal diaphragms), to solid section, the cracking and ultimate torque increase about (43\%) and $(122 \%)$, respectively.

4- When the internal diaphragms changed from opened to closed type, the ultimate capacity increased about $(3.6 \%)$ and $(2.76 \%)$ for beam specimens containing two and four internal diaphragms, respectively. Since the increase is marginal (can be negligible), it can be concluded that the box sections can be made with internal opened diaphragms and possess same capacity or contribution of the closed ones.

5- The toughness of the strengthened beam specimens (by internal closed or opened diaphragms) is higher than the box beam without any strengthening.

\section{References}

1. J. MacGregor, and M. Ghoneim, ACI St. J. 92, 211218 (1995)

2. A. Khalil, E. Etman, A. Atta and S. Fayed, IOSRJMCE, 12, 30-41 (2015)

3. B. Sahib, A. Hameed, and I. Kh.uder, IJMME 12, 754-769 (2012)
4. A. Abeer, A. Allawi, and K. Chai, WASET-IJCSE 7,115-122( 2013)

5. A. Prabaghar, and G. Kumaran, IJCS, 2, 570-594 (2011)

6. H. Okamura and M. Ouchi, JACT 1, 5-15 (2003)

7. ACI Committee $318 \mathrm{M}$, ACI (2014)

8. EFNARC, 21 (2002), Available at (www.efnarc.org)

9. ASTM C39-96, ASTM (1996)

10. BS1881-116, BSI (1983) 